\title{
Program KEMAS untuk Menurunkan Kecemasan pada Dewasa Awal di Masa Pandemi Covid-19
}

\author{
KEMAS Program for Reducing Anxiety in Early Adults during the \\ Covid-19 Pandemic
}

\author{
Syifa Nabila1, Maya Khairani ${ }^{2}$, Kartika Sari ${ }^{3}$, Syarifah Faradina ${ }^{4}$ \\ 1,2,3,4Program Studi Psikologi, Fakultas Kedokteran, Universitas Syiah Kuala
}

Submitted 28 September 2021 Accepted 21 October 2021 Published 30 October 2021

\begin{abstract}
The purpose of this study was to determine the effect of the KEMAS Program for reducing anxiety in early adults during the Covid-19 pandemic. This research was a preexperimental study with a pretest-posttest group design. The study was conducted online involving 36 subjects obtained by incidental techniques. Research data were collected through the DASS-21 anxiety subscale and then analyzed using a non-parametric method, namely the Wilcoxon signed-rank test resulting in coefficient $(z)=-4.584$, and significant value $(p)=0.00$ $(p<0.05)$. The results showed that there was an effect of the KEMAS Program for reducing anxiety in early adults during the Covid-19 pandemic. The results showed a change in the category of anxiety in the subject before and after treatment, namely $80.6 \%$ of the subjects experienced a decrease in anxiety scores; $13.9 \%$ were on the same anxiety score; $5.5 \%$ of subjects experienced an increase in anxiety scores.
\end{abstract}

Keywords: anxiety management; early adulthood; kemas program

Abstrak. Tujuan penelitian ini untuk mengetahui pengaruh Program Kemas terhadap kecemasan pada dewasa awal di masa pandemi Covid-19. Penelitian ini merupakan penelitian praeksperimen dengan desain satu kelompok prates-pascates. Penelitian dilakukan secara daring yang melibatkan 36 subjek yang diperoleh dengan teknik insidental. Data penelitian dikumpulkan melalui subskala kecemasan DASS-21 kemudian dianalisis menggunakan metode non parametrik, yaitu Wilcoxon signed-rank test dengan hasil koefisien $(z)=-4,584$, dan nilai signifikan $(p)=0,00(p<0,05)$. Hasil penelitian menunjukkan bahwa terdapat pengaruh Program Kemas terhadap kecemasan pada dewasa awal di masa pandemi Covid-19. Hasil penelitian menunjukkan adanya perubahan kategori kecemasan pada subjek saat sebelum dan sesudah perlakuan, yaitu $80,6 \%$ subjek mengalami penurunan skor kecemasan; $13,9 \%$ berada pada skor kecemasan yang sama; 5,5\% subjek mengalami peningkatan skor kecemasan.

Kata kunci: dewasa awal; pengelolaan kecemasan; program kemas

Coronavirus Disease 2019 (Covid-19) masuk ke Indonesia sejak Maret 2020 (Kementerian Kesehatan Republik Indonesia, 2020) dan telah menimbulkan dampak yang dirasakan oleh setiap individu dalam berbagai segi kehidupan termasuk berbagai permasalahan psikologis seperti kecemasan (Ahmed et al., 2020; Kazmi et al., 2020; MoghanibashiMansourieh, 2020; Othman, 2020; Zhou et al., 2020). Kecemasan adalah hal yang biasa terjadi dalam keseharian individu, namun kondisi cemas berkepanjangan melemahkan 
sistem kekebalan tubuh yang berakibat pada meningkatnya risiko terinfeksi virus pada masa pandemi Covid-19 (WHO, 2020). Salah satu faktor yang memengaruhi tingkat kecemasan dalam masa pandemi Covid-19 adalah usia. Survei yang dilakukan oleh Persakmi (2020) menunjukkan hasil bahwa kelompok usia 20 - 29 tahun 4,33 kali lebih rentan mengalami gangguan kecemasan dengan tingkat yang lebih tinggi dibandingkan dengan kelompok usia 50 tahun. Berbagai penelitian tentang tingkat kecemasan dan usia selama pandemi terus dilakukan dan ditemukan bahwa kelompok usia yang mengalami tingkat kecemasan lebih tinggi adalah kelompok usia dewasa awal (Czeisler et al., 2020; Perhimpunan Dokter Spesialis Kedokteran Jiwa Indonesia, 2020; Persakmi, 2020; Salari et al., 2020).

Pada masa dewasa awal, individu mulai memikul tanggung jawab yang lebih berat, tidak dapat bergantung dalam hal ekonomi, sosiologis, maupun psikologis pada orang tua (Dariyo, 2003). Damon (dalam McMillin, 2017) menggambarkan masa dewasa awal sebagai masa yang penuh perjuangan dalam mengeksplorasi kehidupan, seperti dalam hal pendidikan, pernikahan, finansial, dan pekerjaan, namun kurang memiliki tujuan jangka panjang, sehingga sering mengakibatkan kecemasan yang dicirikan sebagai ketakutan atau kekhawatiran yang berlebihan. Tak terkecuali pada masa pandemi Covid19, masa dewasa awal pun cukup rentan mengalami kecemasan. Kecemasan yang terjadi pada dewasa awal selama pandemi Covid-19 disebabkan oleh kekhawatiran akan konsekuensi di masa depan, serta adanya tantangan ekonomi yang disebabkan oleh pandemi karena mereka adalah tenaga kerja aktif utama dalam masyarakat (Salari, et al., 2020). Tingkat kecemasan yang lebih tinggi juga dapat terjadi karena akses informasi yang lebih besar melalui sosial media (Cheng, Jun, \& Liang dalam Salari et al., 2020). Mudah dan masifnya penyebaran hoaks seputar Covid-19 melalui media sosial oleh pihak yang tidak bertanggung jawab dapat menimbulkan dampak negatif. Berita yang belum terkonfirmasi kebenarannya, secara psikologis dapat menyebabkan masyarakat bersikap panik, cemas, dan kemudian banyak masyarakat yang melakukan hal-hal di luar akal sehat (Nurrochman, 2020; Satuan Tugas Penanganan Covid-19; 2020).

Dampak yang timbul dari kecemasan dapat mengganggu aktivitas dan produktivitas individu. Oleh karena itu, sangat diperlukan penanganan untuk kecemasan yang tepat serta efektif terutama di masa pandemi Covid-19. Kecemasan merupakan gejala gangguan psikologis awal dan masih sangat mungkin untuk ditangani dan diatasi (Handayani et al., 2020). Penanganan cemas dapat dilakukan dengan terapi psikologi sederhana yang tujuannya menstimulasi pikiran yang positif, seperti relaksasi (Jarnawi, 2020). Selain itu, intervensi lainnya berupa dukungan melalui media sosial ataupun halhal sederhana namun efektif secara ilmiah dapat menjadi upaya dalam mengelola kecemasan dengan lebih baik selama pandemi Covid-19 (Starkman, 2021). Dalam penelitian ini, intervensi psikologis yang dilakukan untuk menurunkan tingkat kecemasan dewasa awal selama pandemi Covid-19 adalah penggabungan dari beberapa kegiatan untuk mengelola kecemasan yang diberi nama Program Kelola Kecemasan 
(KEMAS). Program KEMAS didesain sebagai visualisasi dalam membantu individu untuk semakin memahami kegiatan-kegiatan yang direkomendasikan untuk menjaga kesehatan mental, khususnya untuk mengelola kecemasan.

Adapun yang menjadi acuan peneliti dalam memberikan Program KEMAS adalah kegiatan yang disusun oleh CV. Our Spirit Consultant (2020) yaitu edukasi digital di masa pandemi pengelolaan kecemasan bagi lansia selama pandemi Covid-19 yang menggunakan beberapa teknik yang terbagi menjadi lima kegiatan, yaitu kegiatan Identifikasi Emosi, Titik Stres dan Relaksasi, Self-Talk, Berzikir, dan Bersyukur. Dalam penelitian ini, peneliti menggunakan lima kegiatan serupa yang peneliti modifikasi dari kegiatan yang disusun oleh CV. Our Spirit Consultant dan diberikan kepada kelompok usia yang berbeda, yaitu pada dewasa awal. Kelompok usia dewasa awal dipilih karena beberapa penelitian mengungkapkan bahwa kelompok usia yang mengalami kecemasan paling tinggi adalah dewasa awal (Moghanibashi-Mansourieh, 2020; Zhou et al., 2020; Kazmi et al., 2020; Othman, 2020).

\section{Metode}

\section{Desain penelitian}

Penelitian ini menggunakan metode eksperimen dengan model praeksperimen dengan desain satu kelompok prates-pascates. Model praeksperimen ini sebenarnya kurang ideal disebut sebagai penelitian eksperimen karena banyak hal yang luput dikontrol oleh peneliti saat penelitian dilakukan. Akan tetapi hal ini dipilih karena keterbatasan akses untuk mengadakan pertemuan secara tatap muka langsung karena kasus terkonfirmasi positif covid-19 cukup tinggi terjadi di Aceh, sehingga model ini menjadi pilihan yang paling memungkinkan untuk dilakukan. Adapun kelompok eksperimen adalah dewasa awal yang mengalami kecemasan pada kategori ringan hingga sangat berat, diberikan prates dan pascates berupa subskala kecemasan dari Depression Anxiety and Stress Scale (DASS-21) yang dikembangkan oleh Lovibond dan Lovibond (1995). Kelompok eksperimen mendapatkan perlakuan berupa Program KEMAS yang diadaptasi dari modul edukasi digital di masa pandemi pengelolaan kecemasan bagi lansia yang disusun oleh CV. Our Spirit Consultant (2020).

Adapun proses validasi modul dan video kegiatan dilakukan dengan tahap expert review oleh 5 reviewer dengan latar pendidikan psikologi, kemudian dilakukan uji coba kepada beberapa subjek uji coba, serta menerima beberapa masukan dari setiap reviewer dan subjek uji coba. Berdasarkan validasi modul, didapatkan hasil bahwa secara keseluruhan konten dalam video kegiatan Program KEMAS mudah dipahami, audio serta tampilan menarik dan terdengar dengan jelas, tepat sasaran, serta pemberian instruksi jelas dan mudah diikuti. Namun pada kegiatan titik stres dan relaksasi, satu orang sampel merasa kebingungan saat instruksi kapan harus menutup atau membuka mata, serta terganggu konsentrasi saat instruksi menarik napas dikarenakan narator 
memberikan instruksi menarik napas sebanyak dua kali, sehingga kemudian dilakukan modifikasi lanjutan sesuai dengan masukan yang diberikan.

\section{Partisipan}

Pengambilan sampel menggunakan teknik non-probability sampling, berupa incidental sampling. Dalam pemilihan subjek penelitian, dilakukan tahapan skrining kepada 113 sampel melalui formulir Google menggunakan subskala kecemasan DASS-21 untuk mengetahui tingkat kecemasan subjek penelitian dengan kriteria dewasa awal yang berusia 20-40 tahun, beragama Islam, dan berdomisili di Kota Banda Aceh, kemudian dipilih 43 orang dengan kriteria mengalami kecemasan (dari kategori ringan hingga sangat berat) untuk dijadikan subjek penelitian (hanya 36 subjek yang menyelesaikan kegiatan eksperimen hingga akhir).

\section{Instrumen}

Peneliti melakukan adaptasi subskala kecemasan DASS-21 yang disusun oleh CV. Our Spirit Consultant (2020) dan selanjutnya dievaluasi oleh 3 orang reviewer dengan kualifikasi sebagai dosen psikologi, dan pendidikan terakhir magister/S-2. Subskala kecemasan telah diujicobakan kepada 113 orang dewasa awal dengan rentang usia 20 hingga 40 tahun yang berdomisili di Provinsi Aceh selain Kota Banda Aceh. Hasil uji reliabilitas menunjukkan nilai Cronbach's Alpha sebesar 0,831 dan indeks daya beda butir pernyataan pada rentang nilai 0,444 hingga 0,658. DASS-21 merupakan versi singkat dari skala DASS-42 yang disusun oleh Lovibond dan Lovibond (1995) yang mengukur general psychological distress, yaitu depresi, kecemasan, dan stres individu. Penilaian dalam DASS21 menggunakan skala Likert dengan empat alternatif jawaban (0 hingga 3). Terdapat lima kategori, yaitu normal (skor 0-7), ringan (skor 8-9), sedang (skor 10-14), berat (skor 15-19), dan sangat berat (skor diatas 20). Semakin tinggi skor yang diperoleh individu, maka semakin tinggi tingkat kecemasan yang dialami individu.

\section{Prosedur}

Perlakuan yang diberikan adalah Program Kelola Kecemasan (KEMAS) dengan lima kegiatan, yaitu kegiatan Identifikasi Emosi, Titik Stres dan Relaksasi, Teknik Self-Talk, Terapi Zikir, dan Video Bersyukur. Program KEMAS dilakukan secara berkelompok dengan metode daring, yaitu dilaksanakan dengan memanfaatkan media daring, seperti aplikasi WhatsApp dan Zoom. Metode daring dipilih karena mempertimbangkan protokol kesehatan selama pandemi Covid-19. Penjelasan dari masing-masing kegiatan pada tabel 1. 
Tabel 1.

Penjelasan Kegiatan Program KEMAS

\begin{tabular}{|c|c|c|}
\hline Nama Kegiatan & Isi Kegiatan & Tujuan \\
\hline $\begin{array}{l}\text { Kegiatan 1: } \\
\text { Identifikasi Emosi }\end{array}$ & $\begin{array}{l}\text { Subjek diminta untuk } \\
\text { mengamati tayangan video } \\
\text { intervensi secara daring } \\
\text { yang berisikan edukasi } \\
\text { terkait emosi, stres, dan } \\
\text { cemas }\end{array}$ & $\begin{array}{l}\text { Memberikan pengetahuan kepada subjek } \\
\text { tentang emosi, serta mengajak subjek untuk } \\
\text { mengidentifikasi emosi yang dirasakan. }\end{array}$ \\
\hline $\begin{array}{l}\text { Kegiatan 2: Titik } \\
\text { Stres dan } \\
\text { Relaksasi }\end{array}$ & $\begin{array}{l}\text { Subjek diminta untuk } \\
\text { mengamati video, serta } \\
\text { mengikuti instruksi untuk } \\
\text { memeragakan gerakan- } \\
\text { gerakan pada kegiatan titik } \\
\text { stres dan relaksasi }\end{array}$ & $\begin{array}{l}\text { Melepaskan endorfin, zat penghilang rasa } \\
\text { sakit alami yang diproduksi tubuh untuk } \\
\text { memicu respons menenangkan dan } \\
\text { membangkitkan semangat dalam tubuh, } \\
\text { memiliki efek positif pada emosi, } \\
\text { menyebabkan efek relaksasi, dan } \\
\text { normalisasi fungsi tubuh (Budiarti, 2011). } \\
\text { Menahan terbentuknya respons emosi } \\
\text { negatif seperti stres dan cemas terutama } \\
\text { dalam sistem saraf dan hormon, sehingga } \\
\text { dapat membantu mencegah atau } \\
\text { meminimalkan gejala fisik akibat stres dan } \\
\text { cemas ketika tubuh bekerja keras dalam } \\
\text { menyelesaikan permasalahan sehari-hari } \\
\text { (Widyastusi dalam Resti, 2014). }\end{array}$ \\
\hline $\begin{array}{l}\text { Kegiatan 3: } \\
\text { Teknik Self-Talk }\end{array}$ & $\begin{array}{l}\text { Subjek diminta untuk } \\
\text { mengamati video, serta } \\
\text { mengucapkan kembali } \\
\text { kalimat-kalimat positif } \\
\text { yang disampaikan oleh } \\
\text { instruktur dan mengikuti } \\
\text { gerakan yang dilakukan } \\
\text { oleh instruktur }\end{array}$ & $\begin{array}{l}\text { Menyangkal keyakinan yang tidak masuk } \\
\text { akal dan mengembangkan pemikiran yang } \\
\text { lebih sehat, yang akan menghasilkan self- } \\
\text { talk yang lebih positif agar membuat } \\
\text { individu tetap termotivasi untuk mencapai } \\
\text { tujuan (Pearson, 2001). }\end{array}$ \\
\hline $\begin{array}{l}\text { Kegiatan 4: Terapi } \\
\text { Berzikir }\end{array}$ & $\begin{array}{l}\text { Subjek diminta untuk } \\
\text { mengamati video dan } \\
\text { mengikuti instruksi zikir } \\
\text { dari instruktur }\end{array}$ & $\begin{array}{l}\text { Membantu individu membentuk persepsi } \\
\text { yang lain selain ketakutan, yaitu merasa } \\
\text { yakin bahwa diri manusia selalu berada } \\
\text { dibawah kehendak Allah dalam segala hal } \\
\text { dan urusan (Ash-Shiddieqy, 2001). }\end{array}$ \\
\hline
\end{tabular}




\begin{tabular}{llrl}
\hline Kegiatan 5: Video & Subjek diminta untuk & Mengembangkan emosi individu menjadi \\
Bersyukur & mengamati video serta suatu sikap, sifat moral yang baik, \\
& mendengarkan kalimat- kebiasaan, kepribadian, dan akhirnya akan \\
& kalimat berupa ungkapan memengaruhi individu dalam bereaksi \\
& rasa syukur dengan terhadap sesuatu atau situasi tertentu \\
& berterima kasih atas (Emmons \& McCullough, 2003). \\
& berbagai nikmat yang \\
& diberikan Allah SWT
\end{tabular}

Tahap pelaksanaan eksperimen pada penelitian ini meliputi tahap persiapan, yaitu memberikan informed consent kepada subjek, menyesuaikan jadwal pelaksanaan eksperimen dengan setiap subjek (jadwal pagi pukul 09.00, siang pukul 14.00, sore pukul 17.00, atau malam pukul 20.30), menginformasikan segala hal terkait eksperimen pada grup Whatsapp, dan dilanjutkan dengan tahap pelaksanaan kegiatan eksperimen selama 5 hari pada tanggal 16 - 20 Juni 2021. Pelaksanaan program KEMAS dimulai dengan pembukaan, penjelasan kegiatan yang akan dilakukan mencakup tujuan dan manfaat kegiatan, penayangan video kegiatan, dan penutupan. Jadwal pelaksanaan eksperimen Program KEMAS dapat dilihat pada tabel 2.

\section{Tabel 2.}

Jadwal Pelaksanaan Program KEMAS

\begin{tabular}{llll}
\hline Hari ke- & Jumlah Subjek & Kegiatan & Durasi $^{\text {b }}$ \\
\hline 1 & 38 subjek & Kegiatan 1: Identifikasi Emosi & 17 menit \\
2 & 37 subjek & Kegiatan 2: Titik Stres dan Relaksasi & 26 menit \\
3 & 37 subjek & Kegiatan 3: Teknik Self-Talk & 16 menit \\
4 & 37 subjek & Kegiatan 4: Terapi Berzikir & 25 menit \\
5 & 36 subjek & Kegiatan 5: Video Bersyukur & 15 menit \\
\hline ajumlah subjek yang terlibat penuh hingga akhir penelitian adalah 36 subjek (7 subjek gugur) &
\end{tabular}

Setelah eksperimen, dilakukan pascates pada tanggal 21 Juni 2021, yaitu satu hari setelah Program KEMAS selesai diberikan. Pascates dilaksanakan dalam 4 Jadwal, yaitu jadwal pagi, siang, sore, dan malam secara daring melalui Zoom, dipandu oleh asisten dan diikuti oleh 36 subjek. Analisis Data Analisis data dalam penelitian ini meliputi uji asumsi, yaitu uji normalitas menggunakan Saphiro-Wilk Test, dan uji hipotesis menggunakan uji komparasi nonparametrik dengan teknik Wilcoxon Signed Ranks Test. 
NABILA et al. II PROGRAM KEMAS BAGI DEWASA AWAL

\section{Hasil}

Berikut merupakan data demografi subjek penelitian yang mengikuti Program KEMAS.

\section{Tabel 3.}

Data Demografi Subjek

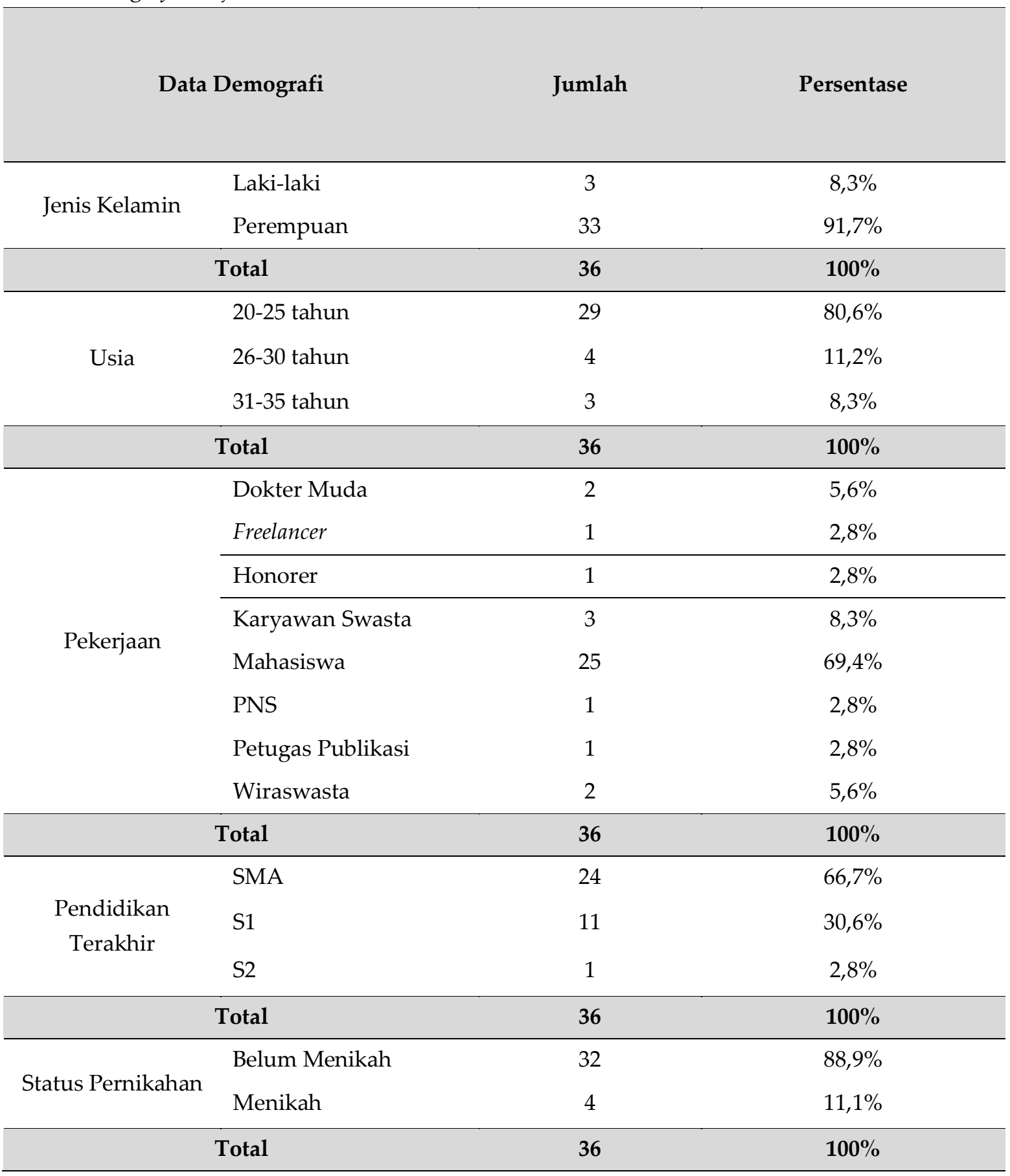

Skor kecemasan setiap subjek kemudian dikategorikan sesuai dengan kategori kecemasan subjek diambil dari kategori subskala Kecemasan DASS-21 oleh Lovibond dan Lovibond (1995) yang terdiri dari lima kategori, yaitu normal, ringan, sedang, berat, dan 
sangat berat. Hasil kategori kecemasan sebelum dan sesudah perlakuan dapat dilihat pada gambar 1.

\section{Gambar 1.}

Perbandingan Kategori Kecemasan Sebelum dan Sesudah Perlakuan

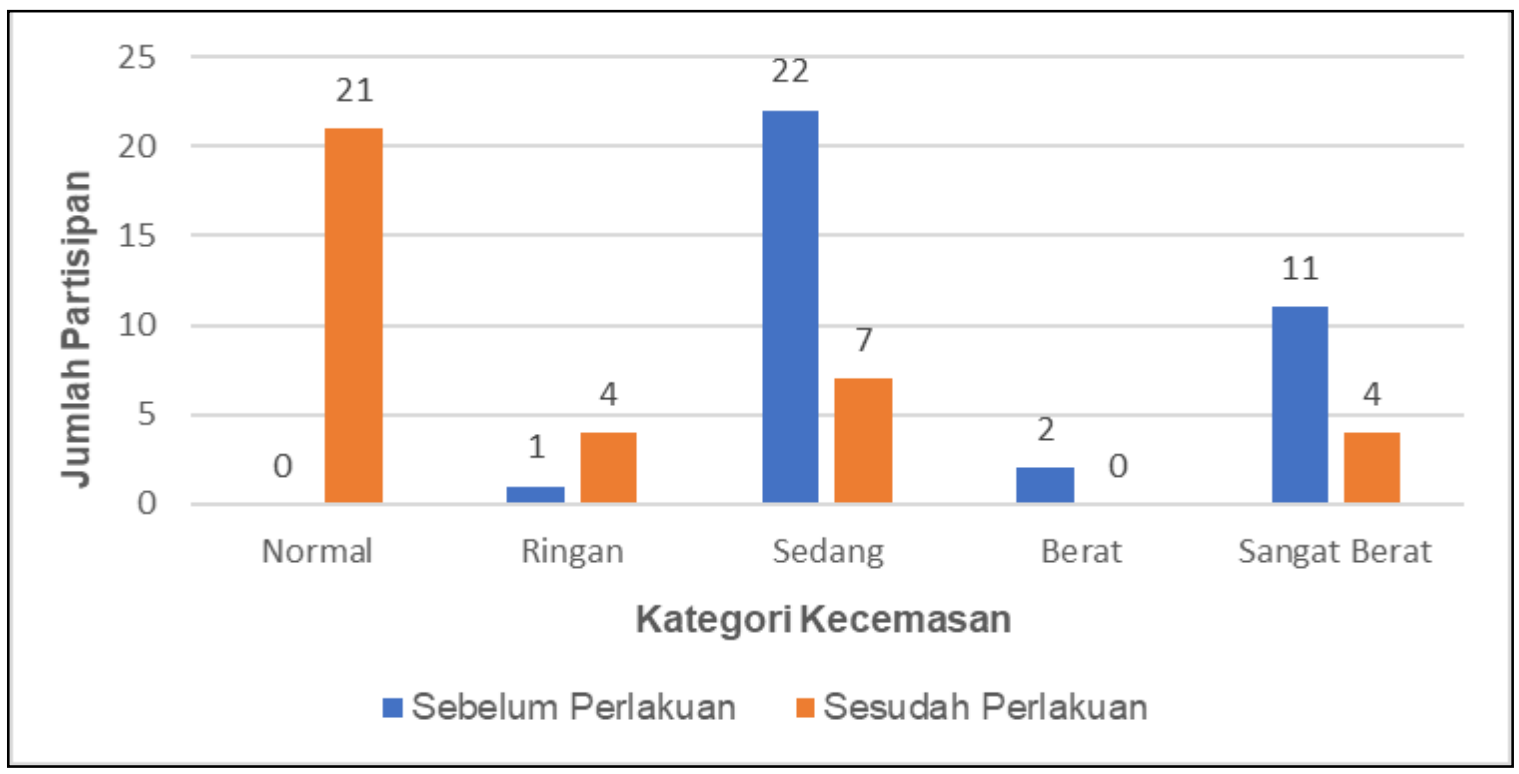

Perubahan jumlah subjek yang mengalami kecemasan dilihat dari kategori kecemasan sebelum dan setelah perlakuan diberikan. Sebelum perlakuan tidak ada subjek yang berada pada kategori normal, namun setelah perlakuan sebanyak 58,3\% (21 subjek) berada pada kategori normal. Kemudian sebelum perlakuan hanya 2,8\% (1 subjek) yang berada pada kategori ringan, namun setelah perlakuan terdapat 11,1\% (4 subjek) yang berada pada kategori ringan. Untuk kategori sedang mengalami penurunan jumlah dari 61,1\% (22 subjek) sebelum perlakuan menjadi 19,5\% (7 subjek) setelah perlakuan. Pada kategori berat, turun dari 5,5\% (2 subjek) menjadi 0, dan pada kategori sangat berat pun mengalami penurunan dari 30,6\% (11 subjek) sebelum perlakuan menjadi 11,1\% (4 subjek) setelah perlakuan.

Tabel 4 dan 5 menjelaskan mengenai analisis uji asumsi yakni uji normalitas dengan menggunakan uji Saphiro-Wilk dan uji hipotesis dengan uji nonparametrik yaitu uji Wilcoxon Signed Rank Test. Berikut merupakan hasil pengujian tersebut.

\section{Tabel 4.}

Analisis Uji Normalitas Saphiro-Wilk

\begin{tabular}{ccccc}
\hline \multirow{2}{*}{ Hasil } & \multirow{2}{*}{ Kelompok } & \multicolumn{3}{c}{ Saphiro-Wilk } \\
\cline { 2 - 5 } & Sebelum Perlakuan & Statistic & $d f$ & Sig. \\
\cline { 2 - 5 } & Sesudah Perlakuan & 0,805 & 36 & 0,000 \\
& 0,727 & 36 & 0,000 \\
\hline
\end{tabular}


Tabel 5.

Analisis Uji Wilcoxon Signed Rank Test Kecemasan

\begin{tabular}{lccccccc}
\hline \multicolumn{1}{c}{ Komponen } & & N & Mean Rank & Sum of Rank & Z & Sig. & Keterangan \\
\hline Kecemasan & NR $^{\mathrm{a}}$ & 29 & 16,6 & 481,50 & $-4.584^{\mathrm{b}}$ & 0,000 & Terdapat \\
Sebelum dan & $\mathrm{PR}^{\mathrm{b}}$ & 2 & 7,25 & 14,50 & & & pengaruh \\
Sesudah Perlakuan & $\mathrm{T}^{\mathrm{c}}$ & 5 & & & & & \\
\hline
\end{tabular}

${ }^{a}$ Negative Rank atau selisih negatif (skor kecemasan menurun)

${ }^{b}$ Positive Rank atau selisih positif (skor kecemasan meningkat)

cTies (kesamaan skor kecemasan sebelum dan sesudah perlakuan)

Berdasarkan nilai signifikansi analisis uji Saphiro-Wilk pada tabel 4 dapat terlihat bahwa data penelitian tidak normal, sehingga dilakukan uji nonparametrik yaitu uji Wilcoxon Signed Rank Test (dapat dilihat pada tabel 5). Interpretasi output uji Wilcoxon menunjukkan negative ranks (selisih negatif) komponen kecemasan pada 29 subjek yang mengalami penurunan dengan nilai rata-rata 16,6 dan sum of rank sebesar 481,5, positive ranks (selisih positif) pada 2 subjek yang mengalami peningkatan dengan nilai rata-rata 7,25 dan sum of ranks sebesar 14,5, serta ties pada 5 subjek yang memiliki kesamaan nilai antara sebelum (prates) dan sesudah perlakuan (pascates). Berdasarkan tabel 5 terlihat pula bahwa hasil menunjukkan nilai signifikansi sebesar 0,000, yakni lebih kecil dari 0,050 yang menunjukkan bahwa hipotesis diterima sehingga dapat disimpulkan terdapat pengaruh Program KEMAS bagi dewasa awal di masa pandemi Covid-19.

\section{Diskusi}

Hasil penelitian ini menunjukkan bahwa terdapat pengaruh Program KEMAS bagi dewasa awal di masa pandemi Covid-19. Hasil ini sejalan dengan beberapa penelitian sebelumnya yang menemukan pengaruh suatu intervensi psikologis terhadap kecemasan pada subjek yang diteliti, seperti pada pasien hemodialisa (Darmawati et al., 2021), ibu praoperasi kanker payudara (Astuti, 2019), dan keluarga yang merawat pasien skizofrenia (Hadiansyah, 2018).

Intervensi berupa program KEMAS memberikan penjelasan dan keterampilan pada individu untuk mengelola kecemasan di masa pandemi Covid-19. Hal ini merupakan salah satu upaya yang dapat dilakukan individu dalam mengatasi efek negatif dari pandemi terutama dalam hal kesehatan mental. Mencari informasi dari berbagai sumber dan menerapkannya dalam kehidupan sehari-hari untuk menjaga kesehatan mental di masa pandemi merupakan suatu langkah positif yang dapat dilakukan oleh individu (Banerjee, 2020). Intervensi sejenis psikoedukasi memberikan perlakuan kepada individu yang berisikan penjelasan yang tepat mengenai permasalahan yang dialami serta dapat dilakukan dari berbagai macam sudut pandang dan dengan berbagai cara (Rodrigues et al., 2018). Kurangnya informasi yang tepat mengenai kondisi 
psikologis individu dapat menyebabkan kecemasan (Dannon et al., 2002). Melalui intervensi yang diberikan, individu belajar untuk bertanggung jawab secara pribadi dalam menghadapi permasalahannya (Bäuml \& Pitschel-Walz, 2003).

Intervensi psikologis seperti psikoedukasi memiliki faktor-faktor terapeutik yang menjadi alat efektif untuk memberikan informasi serta menghilangkan faktor-faktor sikap negatif seperti emosi dan beban yang dirasakan oleh individu, yaitu berkembangnya hubungan baik antara individu dan pemberi intervensi, adanya rasa penghargaan tanpa syarat dan respons empati, perhatian penuh, prosedur yang berorientasi kepada kebutuhan individu, adanya stimulasi berupa harapan dan kepastian, pertukaran pengalaman, dan perasaan bahwa adanya nasib yang sama di antara para individu di dalam kelompok (Bäuml et al., 2006).

Selain itu, dari segi materi program KEMAS, salah satu kegiatan yaitu Terapi Berzikir cocok digunakan di Aceh karena adanya nilai-nilai religiusitas. Hal ini sesuai dengan hasil penelitian yang dilakukan oleh Amalia et al. (2021) yang menyebutkan bahwa masyarakat Aceh menerapkan nilai-nilai religiusitas untuk mampu bertahan menghadapi pandemi Covid-19 dengan melaksanakan ritual keagamaan, mengerjakan sunah-sunah Rasul dan beribadah, termasuk berzikir.

Peneliti menganalisis perubahan skor kecemasan subjek sebelum dan sesudah diberikan Program KEMAS dan diketahui sebanyak 80,6\% (29 subjek) mengalami penurunan skor kecemasan, sebanyak $13,9 \%$ (5 subjek) berada pada skor yang sama, namun terdapat 5,5\% (2 subjek) yang justru skor kecemasannya mengalami peningkatan sesudah diberikan perlakuan. Sebagian besar individu mengambil banyak manfaat dari Program KEMAS, namun terdapat pula individu yang harus diberikan intervensi yang lebih untuk menangani kecemasan, seperti diberikan psikoterapi secara individual (Houghton \& Saxon, 2007). Berdasarkan evaluasi, dua orang subjek yang mengalami peningkatan skor menuliskan pengalaman saat mengikuti program sedang berada dalam kondisi yang sangat cemas dikarenakan banyaknya stressor yang sedang dihadapi, ditambah lagi kecemasan yang sudah lama dialami, serta salah satu subjek mengatakan bahwa dirinya tidak dapat berkonsentrasi saat menyaksikan video kegiatan dikarenakan banyaknya beban pikiran.

Intervensi berupa Program KEMAS lebih menekankan pada komponen kognitif daripada komponen afektif. Hal ini dikarenakan teori yang melatarbelakangi intervensi sejenis psikoedukasi salah satunya adalah teori kognitif yang berfokus pada penguasaan keterampilan kognisi-emosi yang menjadi komponen dari proses psycho-training (Lukes \& McFarlane, 2004). Intervensi psikologis berupa kegiatan untuk mengelola kecemasan digunakan untuk membantu mengatasi segala hambatan individu untuk memahami dan mencerna informasi yang kompleks untuk mengembangkan strategi penggunaan informasi secara proaktif. Berdasarkan penjelasan tersebut, peningkatan skor kecemasan pada dua subjek dapat terjadi karena subjek membutuhkan penanganan yang lebih dari psikoedukasi. 
Menurut Lovibond dan Lovibond (1995) kecemasan merupakan suatu keadaan negatif pada seseorang yang ditandai dengan adanya rangsangan saraf otonom, respons otot rangka, kecemasan situasional, dan perasaan cemas yang subjektif. Dalam subskala Kecemasan DASS-21, tingkat kecemasan yang diukur adalah dalam jangka waktu satu minggu terakhir. Hasil penelitian ini menunjukkan bahwa terdapat perbedaan perubahan kategori kecemasan, yaitu terdapat subjek yang kecemasannya menurun, tetap, dan terdapat pula subjek yang kecemasannya meningkat. Hal ini dapat dipengaruhi oleh kemampuan individu dalam merespons kecemasan. Kemampuan individu dalam merespons kecemasan dapat dipengaruhi oleh beberapa faktor, seperti sifat stresor yang dapat berubah secara tiba-tiba atau berangsur-angsur, adanya stresor yang harus dihadapi secara bersamaan, dan lamanya stresor (Rasmun, 2004). Melalui Program KEMAS, individu diberikan intervensi untuk dapat mengelola kecemasannya. Pengelolaan kecemasan yang dilakukan merupakan sebuah cara untuk mengurangi kecemasan yang mengganggu agar tidak menghambat kehidupan sehari-hari, namun tidak menghilangkan rasa cemas secara keseluruhan. Hal ini dikarenakan rasa cemas pada individu juga dapat menjadi motivasi untuk menjadi lebih baik, positif, dan waspada dalam berbagai situasi dan kondisi (Endriyani et al., 2021).

\section{Keterbatasan penelitian}

Penelitian mengenai pengaruh Program KEMAS bagi dewasa awal di masa pandemi Covid-19 masih memiliki banyak keterbatasan, di antaranya adalah terlalu luasnya kriteria inklusi subjek, sehingga berdampak pada kemungkinan adanya variabel ekstraneous, seperti latar belakang pendidikan, pekerjaan, dan status sosial. Kemudian tidak adanya informasi mengenai peristiwa atau jenis stressor apa saja yang dialami oleh subjek dalam satu minggu terakhir selama pelaksanaan perlakuan eksperimen, perubahan historis subjek, dan kematangan yang dapat dialami subjek, sehingga mungkin dapat memengaruhi hasil penelitian.

Pemilihan waktu yang berbeda-beda dan jumlah subjek yang terlibat dalam setiap waktu pelaksanaan kegiatan juga dapat berpengaruh terhadap hasil eksperimen. Hal ini menjadi keterbatasan peneliti dikarenakan kegiatan tidak dapat dilakukan secara tatap muka dan dalam satu waktu mengingat kondisi pandemi, sehingga harus menyesuaikan dengan keluangan waktu subjek dan hal ini tidak dikontrol lebih lanjut dalam penelitian ini dan cukup memakan waktu serta tenaga yang cukup banyak. Berdasarkan hasil evaluasi oleh subjek penelitian, dari segi konten dan durasi pelaksanaan kegiatan intervensi terlalu singkat pada setiap kegiatannya dan penjelasan teoritis tentang setiap kegiatan perlu diperbanyak. Dalam penelitian ini juga belum dilakukan follow-up dengan melakukan pengukuran kembali setelah pasca-tes, sehingga belum dapat dipastikan bahwa perubahan kecemasan yang dialami bersifat menetap atau hanya sementara.

Adapun tantangan yang dihadapi adalah pemberian Program KEMAS dilakukan melalui video yang menyebabkan asisten peneliti tidak dapat berinteraksi secara tatap 
muka langsung dengan subjek dan tidak dapat mengontrol gangguan-gangguan yang ada di sekitar subjek saat mengikuti eksperimen, sehingga hal ini juga dapat memengaruhi hasil penelitian. Kendala yang dihadapi subjek dalam penelitian ini didapatkan melalui formulir evaluasi. Melalui formulir evaluasi, subjek memberikan saran yang membangun untuk penelitian ini, yaitu pada video kegiatan Identifikasi Emosi, Teknik Self-Talk, Terapi Berzikir, dan Video Bersyukur, sebanyak 16,7\% subjek (6 orang) memberi saran untuk memperpanjang durasi video agar subjek dapat lebih memahami dan menghayati setiap informasi serta instruksi yang diberikan. Selain itu, terdapat pula subjek yang memberi saran bahwa sebaiknya menggunakan latar yang polos pada video kegiatan terapi berzikir agar tidak mengganggu fokus.

\section{Kesimpulan}

Penelitian ini menyimpulkan bahwa Program KEMAS dapat menurunkan kecemasan dewasa awal di masa pandemi Covid-19. Secara keseluruhan, hasil penelitian ini menemukan bahwa terdapat perubahan skor kecemasan pada 36 subjek pada saat sebelum dan sesudah diberikan perlakuan.

\section{Saran}

Peneliti selanjutnya diharapkan mampu lebih memerhatikan beberapa hal, seperti modul dan video Program KEMAS dari segi konten dan durasi pada setiap videonya. Durasi dapat ditambahkan dan dari segi konten harus diberikan penjelasan lebih mengenai pengetahuan teoretis tentang pengelolaan kecemasan. Kemudian desain penelitian dapat dilakukan dengan eksperimen kuasi agar lebih banyak hal yang terkontrol, seperti memberikan buku pegangan yang berisi materi maupun untuk menulis peristiwa yang dialami oleh subjek setiap harinya selama penelitian, melaksanakan penelitian secara luring dalam satu waktu saja secara bersamaan, menambah jumlah subjek, memperkecil kriteria inklusi subjek, melakukan follow-up kembali pascates, serta dapat meneliti pada kelompok usia yang berbeda agar penelitian ini dapat dikaji lebih luas lagi.

\section{Ucapan terima kasih}

Penulis mengucapkan terima kasih kepada ibu Maya Khairani, M.Psi., Psikolog, ibu Kartika Sari, S.Psi., M.Si., Psikolog, ibu Syarifah Faradina, M.Psi., Psikolog, seluruh subjek penelitian, asisten penelitian, Dinda Anisa, Isra Ajria, Cut Almira Islamey, dan Fitri Auliani yang telah banyak membantu dalam proses pengumpulan data, dan kepada Program Studi Psikologi Fakultas Kedokteran Universitas Syiah Kuala. 


\section{Kontribusi penulis}

SN berkontribusi dalam menyusun naskah, merancang penelitian, mengumpulkan data, dan menganalisis data. MK merancang penelitian, membaca dan mengedit naskah. KS dan SF membaca dan mengedit naskah.

\section{Konflik kepentingan}

Penulis menyatakan tidak ada konflik kepentingan dalam penelitian, penulisan, dan/atau pulikasi naskah ini.

\section{Pendanaan}

Penelitian Program KEMAS untuk menurukan kecemasan pada dewasa awal di masa pandemi Covid-19 didanai oleh penulis SN.

\section{ORCID ID}

https://orcid.org/0000-0002-4472-8234

\section{Kepustakaan}

Ahmed, M. Z., Ahmed, O., Aibao, Z., Hanbin, S., Siyu, L., \& Ahmad, A. (2020). Epidemic of COVID-19 in China and associated psychological problems. Asian Journal of Psychiatry, 51, 102092. https://doi.10.1016/j.jap.2020.102092.

Amalia, I., Suzanna, E., \& Adyani, L. (2021). Peran religiusitas bagi masyarakat Aceh dalam menghadapi pandemi Covid-19. Jurnal Diversita, 7(1), 79-84.

Ash-Shiddieqy, T. M. H. (2001). Al-Islam Jilid 1. PT. Pustaka Rizki Putra.

Astuti, T., Desvianti, R. A., \& Bangsawan, M. (2019). Pengaruh psikoedukasi terhadap kecemasan ibu pre-operasi kanker payudara. Jurnal Kesehatan, 10(1), 121-126.

Banerjee, D. (2020). The COVID-19 putbreak: Crucial role the psychiatrist can plat. Asian J. Psychiatr. https://doi.org/10.1016/j.1jp.2020.102014

Bäuml, J., \& Pitschel-Walz, G. (2003). Psychoedukation bei schizophrenen erkrankungen.

Bäuml, J., Froböse, T., Kraemer, S., Rentrop, M., \& Pitschel-Walz, G. (2006). Psychoeducation: A basic psychotherapeutic intervention for patients with schizophrenia and their families. Shizophrenia Bulletin, 32(S1-S9).

Budiarti, K. D. (2011). Hubungan akupresur dengan tingkat nyeri dan lama persalinan pada ibu primipara di Garut (Tesis tidak dipublikasikan). Fakultas Ilmu Keperawatan, Universitas Indonesia.

Czeisler, M. É., Lane, R. I., Petrosky, E., Wiley, J. F., Christensen, A., Njai, R., ... \& Rajaratnam, S. M. (2020). Mental health, substance use, and suicidal ideation during the COVID-19 pandemic-United States, June 24-30, 2020. Morbidity and Mortality Weekly Report, 69(32), 1049.

Dannon, P., Lancu, I., \& Grunhaus, L. (2002). Psychoeducation in panic disorder patients: Effect of self-information booklet in a randomized, masked-rater study. Depression and Anxiety, 16(2), 71-76. 
Dariyo, A. (2003). Psikologi perkembangan dewasa muda. PT Gramedia.

Darmawati, Z. R., Supriyatno, H., \& Widigdo, D. A. M. The influence of pshycoeducation therapy toward anxiety level in hemodialysis patients. Media Karya Kesehatan, 4(1), 118-128. https://doi.org/10.24198/mkk.v4i1.30340.g15505

Emmons, R. A., \& McCullough, M. E. (2004). The psychology of gratitude. Oxford University Press, Inc..

Endriyani, S., Damanik, H. D. L., \& Pastari, M. (2021). Upaya mengatasi kecemasan masyarakat di masa pandemi Covid-19. Jurnal Pengabdian Kepada Masyarakat, 5(1), 172-183.

Hadiansyah, T. (2018). Efektivitas intervensi psikoedukasi terhadap tingkat kecemasan keluarga dalam merawat klien skizofrenia. Jurnal Skolastik Keperawatan, 4(2), 49-61. https://doi.org/10.35974/jsk.v4i2.715

Houghton, S., \& Saxon, D. (2007). An evaluation of large group CBT psycho-education for anxiety disorders delivered in routine practice. Patient Education and Counseling, 68(1), 107-110.

Jarnawi. (2020). Mengelola cemas di tengah pandemik corona. Jurnal At-Taujih: Bimbingan dan Konseling Islam, 3(1), 60-73.

Kazmi, S. S. H., Hasan, D. K., Talib, S., \& Saxena, S. (2020). COVID-19 and lockdwon: a study on the impact on mental health. Available at SSRN 3577515.

Kementerian Kesehatan Republik Indonesia. (2020). Pedoman pencegahan dan pengendalian Coronavirus Disease (Covid-19). Diakses melalui https://covid19.go.id

Lovibond, S. H., \& Lovibond, P. F. (1995). Manual for the Depression Anxiety Stress Scales (Edisi kedua). Psychology Foundation. Diakses melalui https://www2.psy.unsw.edu.au

McMillin, J. F. (2017). The paradox of choice in emerging adulthood: Anxiety and ambivalence (Tesis tidak dipublikasikan). Bowling Green State University.

Moghanibashi-Mansourieh, A. (2020). Assessing the anxiety level of Iranian general population during COVID-19 outbreak. Asian Journal of Psychiatry, 51, 102076.

Nurrochman. (2020, Maret). Corona, hoaxs, dan kecemasan publik. Jalandamai.org. Diakses melalui https://jalandamai.org/corona-hoaks-dan-kecemasan-publik.html

Othman, N. (2020). Depression, anxiety, and stress in the time of COVID-19 pandemic in Kurdistan region, Iraq. Kurdistan Journal of Applied Research, 37-44.

Pearson. (2001). Develop the habit of healthy self-talk. Diakses dari https://healthy habits.com/selftalk.asp

Persakmi. (2020, Juni). Mayoritas masyarakat Indonesia alami kecemasan di masa pandemi Covid-19. Diakses melalui https://persakmi.or.id

Resti, I. B. (2014). Teknik relaksasi otot progresif untuk mengurangi stres pada penderita asma. Jurnal Ilmiah Psikologi Terapan, 2(1), 1-20.

Salari, N., Hosseinian-Far, A., Jalali, R., Vaisi-Raygani, A., Rasoulpoor, S., Mohammadi, M., ... \& Khaledi-Paveh, B. (2020). Prevalence of stress, anxiety, depression among 
the general population during the COVID-19 pandemic: a systematic review and meta-analysis. Globalization and Health, 16(1), 1-11. https://doi.org/10.1186/s12992020-00589-w

Satuan Tugas Penanganan Covid-19. (2020, Mei). Tips kesehatan jiwa menghadapi situasi dampak pandemi Covid-19. Covid19.go.id. Diakses melalui https://covid19.go.id/p/berita/tips-kesehatan-jiwa-menghadapi-situasi-dampakpandemi-Covid-19.

Starkman, M. (2020). Managing anxiety during the Covid-19 pandemic. Diakses dari https://michigan.umich.edu

World Health Organization. (2020). Coronavirus disease (Covid-19) outbreak. WHO. Diakses melalui https://www.who.int

Zhou, S. J., Zhang, L. G., Wang, L. L., Guo, Z. C., Wang, J. Q., Chen, J. C., ... \& Chen, J. X. (2020). Prevalence and socio-demographic correlates of psychological health problems in Chinese adolescents during the outbreak of COVID-19. European Child $\mathcal{E}$ Adolescent Psychiatry, 29(6), 749-758. 